\title{
Gram-typing of mastitis bacteria in milk samples using flow cytometry
}

\author{
S. N. Langerhuus, ${ }^{* 1}$ K. L. Ingvartsen, ${ }^{*}$ T. W. Bennedsgaard, ${ }^{*}$ and C. M. Røntved† \\ *Department of Animal Science, Faculty of Science and Technology, Aarhus University, Blichers Allé 20, Tjele, Denmark \\ †CMR On-Site, Skjernvej 4A, 9220 Aalborg Øst, Denmark
}

\section{ABSTRACT}

Fast identification of pathogenic bacteria in milk samples from cows with clinical mastitis is central to proper treatment. In Denmark, time to bacterial diagnosis is typically 24 to $48 \mathrm{~h}$ when using traditional culturing methods. The PCR technique provides a faster and highly sensitive identification of bacterial pathogens, although shipment of samples to diagnostic laboratories delays treatment decisions. Due to the lack of fast on-site tests that can identify the causative pathogens, antibiotic treatments are often initiated before bacterial identification. The present study describes a flow cytometry-based method, which can detect and distinguish gram-negative and gram-positive bacteria in mastitis milk samples. The differentiation was based on bacterial fluorescence intensities upon labeling with biotin-conjugated wheat germ agglutinin and acridine orange. Initially 19 in-house bacterial cultures (4 gramnegative and 15 gram-positive strains) were analyzed, and biotin-conjugated wheat germ agglutinin and acridine orange florescence intensities were determined for gram-negative and gram-positive bacteria, respectively. Fluorescence cut-off values were established based on receiver operating characteristic curves for the 19 bacterial cultures. The method was then tested on 53 selected mastitis cases obtained from the department biobank (milk samples from 6 gram-negative and 47 gram-positive mastitis cases). Gram-negative bacteria in milk samples were detected with a sensitivity of 1 and a specificity of 0.74 , when classification was based on the previously established cut-off values. However, when receiver operating characteristic curves were constructed for the 53 mastitis cases, results indicate that a sensitivity and specificity of 1 could be reached if cut-off values were reduced. This flow cytometry-based technique could potentially provide dairy farmers and attending veterinarians with on-site information on bacterial gram-type and prevent ineffective antimicrobial

Received June 6, 2012.

Accepted September 18, 2012.

${ }^{1}$ Corresponding author: Sine.Langerhuus@agrsci.dk treatment in mastitis cases caused by gram-negative bacteria.

Key words: gram-type, bacterial pathogen, bovine mastitis, flow cytometry

\section{INTRODUCTION}

Mastitis caused by bacterial pathogens is of major economic importance because it decreases milk yield and milk quality, increases the risk of early culling, and adds on to the daily work load (Seegers et al., 2003). Furthermore, mastitis compromises animal welfare (Rasmussen et al., 2011; Fogsgaard et al., 2012). An early identification of the pathogenic bacteria is essential to treatment (Pinzón-Sánchez and Ruegg, 2011). In Denmark, milk samples from cows with clinical or subclinical mastitis (high SCC) are commonly grown on blood agars for 24 to $48 \mathrm{~h}$ and bacterial pathogens are identified by the attending veterinarian based on colony morphology and taxonomic tests [i.e., KOH string test, oxidase, catalase, and Christie, Atkins, Munch-Petersen (CAMP) reactions]. At present, the use of a commercial PCR kit for detection of mastitis pathogens (Koskinen et al., 2009) is increasing in some Northern European countries such as Finland, Denmark, and Germany, the method being a highly sensitive technique for bacterial detection. The technique does not require overnight incubation and, consequently, bacterial identification times are also considerably reduced (6 h; Koskinen et al., 2009; Shome et al., 2011). However, at present, the PCR technique is not economically accessible for onsite solutions and, consequently, shipment of samples to diagnostic laboratories prolongs bacterial identification times. Other concerns regarding the PCR technique are the identification of numerous bacteria in each milk sample, including bacteria that may not originate from the udder, the inability to distinguish between live and dead bacteria, and the inability to obtain antibiograms.

In Denmark, the treatment of clinical mastitis is, therefore, often initiated before final bacterial diagnosis, and consequently ineffective antibiotic treatment of gram-negative bacterial infections occurs regularly. The development of a fast on-site solution that can determine bacterial gram-type with minimal preincu- 
bation could potentially reduce the ineffective use of antibiotics in gram-negative mastitis cases.

The original Gram staining procedure was first described by Christian Gram and his colleague Carl Friedlander back in the 1880s (Madigan et al., 2009). At present, the $\mathrm{KOH}$ string test is a simpler and less labor-intensive test for gram typing of bacteria, grampositive bacteria being identified with $100 \%$ sensitivity and $99 \%$ specificity (Arthi et al., 2003).

Flow cytometry is a commonly used technique for quantifying bacteria in bulk milk (Gunasekera et al., 2003; Holm and Jespersen, 2003), milk powder (Flint et al., 2007), and dairy starters (Bunthof and Abee, 2002), and it is presently used for quantification of bacteria in several commercial instruments such as the BactoScan (Foss Electric A/S; Hillerød, Denmark), BactoCount (Bentley Instruments Inc., Chaska, MN), and BactiFlow ALS (AES Chemunex Inc., Cranbury, NJ). In addition, flow cytometry-based methods have also been used for gram-typing bacteria in bulk milk when labeling with DNA-associated fluorochromes and fluorochromeconjugated lectins (Gunasekera et al., 2003; Holm and Jespersen, 2003). The same principle could potentially be used for gram-typing of mastitis-associated bacteria in individual cow or quarter milk samples. However, the flow cytometry-based method has not been further developed for mastitis diagnostics because of difficulties in analyzing nonhomogeneous mastitis milk samples, the background noise caused by high SCC, a relatively poor detection limit, and misclassification due to contaminating bacteria.

In the present study, a new adapted procedure for identification and gram-typing of bacteria in mastitis milk samples is described. Diluted and preincubated mastitis milk samples were labeled with a combination of biotin-conjugated wheat germ agglutinin (WGA) and acridine orange (AO) and their fluorescence intensities were measured by flow cytometry. The hypotheses were that bacterial populations in mastitis milk with high SCC could be detected and that gram-negative and gram-positive bacterial populations could be distinguished using flow cytometry.

\section{MATERIALS AND METHODS}

\section{In-House Bacterial Cultures}

Nineteen different bacterial strains/isolates were evaluated in the study (Table 1 ). The bacteria included 15 commercial reference strains and 4 bovine field isolates from other Danish laboratories; among these, 15 were gram-positive and 4 were gram-negative bacterial strains. The bacteria listed are referred to as in-house bacteria. The in-house bacteria were used to establish the method presented and to determine the receiver operating characteristic (ROC) curves and cut-off values as described in the data analysis section.

Bits of frozen bacterial culture $\left(-20^{\circ} \mathrm{C}\right)$ were scraped onto blood agars (Eurofins Steins Laboratory A/S, Holstebro, Denmark) and BD CHROMagar Orientation Mediums (BD Diagnostic Systems, Heidelberg, Germany). Both agars were incubated at $37^{\circ} \mathrm{C}$ overnight and were evaluated for viable monocultures the following day. One colony from blood agars of each bacterial monoculture was transferred to $3 \mathrm{~mL}$ of brain heart infusion (BHI) broth (Merck KGaA, Darmstadt, Germany) and incubated at $37^{\circ} \mathrm{C}$ overnight before fluorochrome labeling and flow analysis were performed (Figure 1).

\section{Mastitis Milk Samples}

In total, 53 quarter milk samples from cows with mastitis were selected from the Department of Animal Science (Aarhus University, Tjele, Denmark) biobank and included in the study. Quarter milk samples were taken out aseptically, as initial jets of milk were discarded and teat openings were wiped with $70 \%$ ethanol before sample collection. The SCC was determined on fresh milk in the barn using a DCC cell counter (DeLaval A/S, Vejle, Denmark). Milk samples were frozen immediately after collection $\left(-20^{\circ} \mathrm{C}\right)$. Samples were transported from dairy farms to the laboratory, where they were stored at $-20^{\circ} \mathrm{C}$ upon arrival. Milk samples were incubated on blood agars (Eurofins Steins Laboratory A/S) and on BD CHROMagar Orientation Mediums (BD Diagnostic Systems) at $37^{\circ} \mathrm{C}$. The agars were read after 24 and $48 \mathrm{~h}$. Pathogens were identified by classical bacteriologic procedures (i.e., colony morphology, $\mathrm{KOH}$ string test, oxidase, catalase, coagulase, and CAMP reactions). Staphylococcus aureus and Streptococcus dysgalactiae mastitis cases were confirmed using Slidex Staph-Kit and Slidex Strepto Plus, respectively; both kits were from BioMérieux (Marcy L'Étoile, France). Type B streptococci with a positive CAMP test were sent to a diagnostic laboratory (Eurofins Steins Laboratory A/S) according to the national guidelines. The milk samples were then included in the biobank at the Department of Animal Science (Aarhus University). Prior to flow analysis, the milk samples were thawed and $50 \mu \mathrm{L}$ was transferred to $5 \mathrm{~mL}$ of BHI broth (Merck KGaA) for incubation at $37^{\circ} \mathrm{C}$ overnight (Figure 1). The following day, the samples of the incubated milk in BHI broth were transferred to blood agars (Eurofins Steins Laboratory A/S) and BD CHROMagar Orientation media (BD Diagnostic Systems) and incubated at $37^{\circ} \mathrm{C}$ overnight. Classical bacteriological procedures were repeated to confirm bacterial viability and the previous bacteriological identification. 
In-house bacterial strain was transferred
Gram-typing by

flow analysis

\section{to agar \\ A

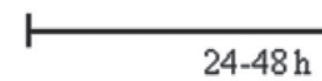
A bacterial colony was transferred to BHI broth


tavidin (BD Pharmingen, Franklin Lakes, NJ) and 4.2 $\mu \mathrm{L}$ of sterile $0.9 \%$ saline, and the conjugated complex was then left in the dark for 30 min. $3-N, 3-N, 6-N, 6-$ $\mathrm{N}$-Tetramethylacridine-3,6-diamin (AO; Invitrogen, Nærum, Denmark) was used in a stock solution of 10 $\mathrm{mg} / \mathrm{mL}$ of water.

Samples with in-house bacterial cultures incubated overnight in BHI broth were diluted with saline to an expected bacterial concentration of $10^{6}$ bacteria $/ \mathrm{mL}$. The diluted samples $(500 \mu \mathrm{L})$ were initially labeled with $5 \mu \mathrm{L}$ of biotin-conjugated allophycocyanin (APC) streptavidin-WGA complex and left in the dark for 10 min. Then, samples were labeled with $1 \mu \mathrm{L}$ of $\mathrm{AO}$ stock solution and left in the dark for $5 \mathrm{~min}$, and immediately thereafter flow analyses were performed. Bacterial pathogens in mastitis milk samples preincubated overnight in BHI broth $(500 \mu \mathrm{L})$ were labeled according to the protocol for the in-house bacterial cultures described above.

\section{Flow Analysis}

Flow analyses of the in-house bacterial cultures and milk samples were conducted on a BD FACS-Canto Flow Cytometer (BD Biosciences, San Jose, CA) equipped with a blue laser (488 nm) using forward scatter (FSC) and side scatter (SSC) signals and green (525-nm) fluorescent signals, and with a red laser $(635 \mathrm{~nm})$ using red (661-nm) fluorescent signals. Voltage settings for FSC, SSC, fluorescein isothiocyanate (FITC), and APC channels were $250,375,400$, and 600 , respectively. The detectors were all set to logarithmic amplification. The SSC threshold was set at 200, whereas no threshold was set for FSC; however, all events with an FSC below 400 were eliminated by gating (Figure 2). The flow analyses were performed without compensation. Day-to-day alignment was performed using BD FACS 7-color setup beads (BD Biosciences) and gram-positive and gram-negative controls. Flow analyses were performed using a low flow rate and analyses were stopped after 3 min or when total events in the Q1-1 and Q2-1 gates reached 5,000 (Figure 2). Based on flow analyses from 7 sterile milk samples with SCC $<100,000$ cells/ $\mathrm{mL}$, the gate Q1-1 was set to eliminate unspecific binding (artifacts) from milk components observed in gate Q2-1 (Figure 2). During the flow analysis of milk samples, the in-house bacterial cultures Staph. aureus (no. 1) and Escherichia coli (no. 16) were included as gram-positive and gram-negative controls, respectively (Figure 2). The day-to-day coefficients of variation for Staph. aureus were 1.6\% (AO FITC) and 1.1\% (WGA APC), and for E. coli they were $3.7 \%$ (AO FITC-H) and $2.8 \%$ (WGA APC). The gates shown in Figure 2 were applied in all of the flow analyses performed.

\section{Data Analysis}

In-house bacterial cultures were plotted with respect to AO FITC mean fluorescence intensity (MFI) and WGA APC MFI to evaluate the distribution pattern for gram-negative and gram-positive bacteria, respectively. A linear model was fitted to the AO FITC MFI and WGA APC MFI variables, with gram-type included as a fixed effect. The MFI values were $\log$ transformed before statistical analysis and results are expressed as medians with corresponding $95 \%$ confidence intervals. Median MFI values in mastitis milk samples were also determined for gram-negative and gram-positive cases and for the individual pathogens.

The sensitivity and specificity for the present Gramstaining method were calculated from the results of the 53 mastitis cases based on AO FITC and WGA APC MFI cut-off values determined for the in-house bacterial cultures. The golden standard for bacterial gram-type used in the calculation of reported sensitivities and specificities was the reported gram-type for all in-house bacterial cultures and gram-type results obtained with the $\mathrm{KOH}$ string test for all bacterial pathogens in mastitis cases. Cut-off values were identified for in-house bacterial cultures AO FITC and WGA APC MFI based on individual ROC curves. In addition, ROC curves with an added smooth function were constructed for AO FITC and WGA APC MFI in mastitis cases.

For all the statistical analyses performed, significance was stated at the $5 \%$ level. Data were analyzed using the software R (R Development Core Team, 2012; http://www.R-project.org).

\section{RESULTS}

\section{In-House Bacterial Cultures}

In Figure 3, the AO FITC MFI for the 19 in-house bacterial cultures was plotted against the WGA APC MFI. The median AO FITC was 6,066 $(3,779 ; 9,735)$ MFI and 16,267 $(12,742 ; 20,767)$ MFI for gram-negative and gram-positive bacteria cultures, respectively, and differed significantly $(P=0.002)$. The median WGA APC was 289 (87; 964) MFI for gram-negative bacteria cultures, which was significantly lower than the 1,402 $(753 ; 2,611)$ MFI for the gram-positive bacteria cultures $(P=0.036)$. The cut-off values with corresponding sensitivity and specificity are presented on the ROC curves shown in Figure 4.

\section{Mastitis Milk Samples}

In total, 53 mastitis milk samples from cows with clinical mastitis were included in the study, the mean 

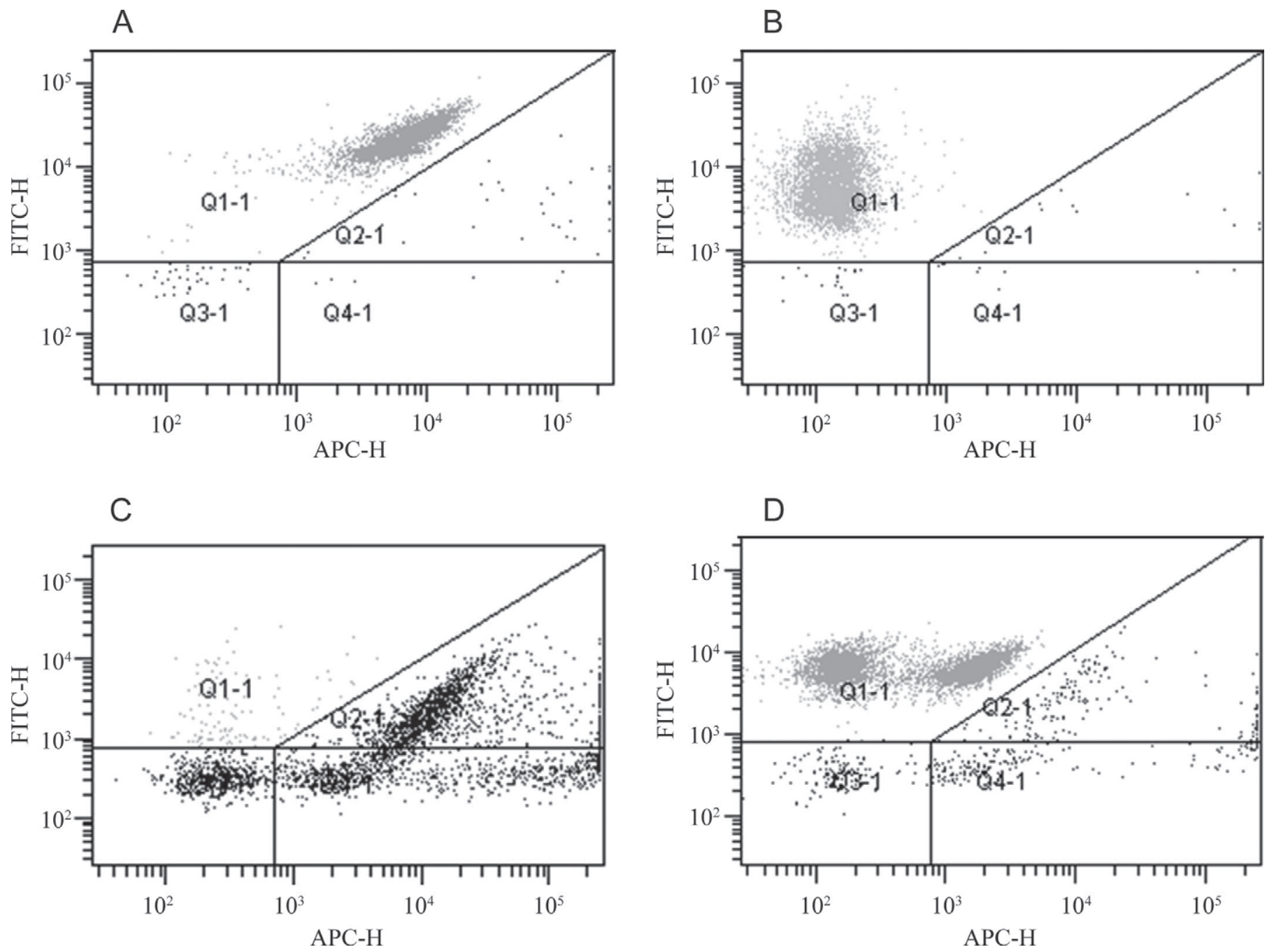

Figure 2. (A) Gram-positive in-house bacterial culture (no. 1; Staphylococcus aureus); (B) gram-negative in-house bacterial culture (no. 16; Escherichia coli); (C) sterile milk sample with low SCC; (D) mixed sample. The gate Q1-1 was set to include gram-negative and gram-positive controls and Q2-1 to eliminate artifacts from unspecific staining of milk components. Fluorescein isothiocyanate (FITC-H) mean fluorescence intensity (MFI) for labeling with acridine orange (AO) and allophycocyanin (APC-H) MFI for labeling with wheat germ agglutinin (WGA) are shown.

SCC was $2.2 \times 10^{6} / \mathrm{mL}\left(\mathrm{SD} 1.8 \times 10^{6} / \mathrm{mL}\right)$. The samples included 6 gram-negative bacterial pathogens [i.e., E. coli $(\mathrm{n}=6)$ ], and 47 gram-positive bacterial pathogens [i.e., CNS $(\mathrm{n}=17)$, Staph. aureus $(\mathrm{n}=7)$, Streptococcus agalactiae $(\mathrm{n}=1)$, Strep. dysgalactiae (n $=6)$, Streptococcus uberis $(\mathrm{n}=6)$, and Enterococcus faecalis $(\mathrm{n}=10)]$. The AO FITC MFI and WGA APC MFI were significantly different in gram-negative compared with gram-positive bacterial pathogens, with $P$ $=0.002$ and $P<0.001$, respectively (Figure 5). In addition, significant differences among the individual bacterial pathogens were observed. The AO FITCH MFI was significantly lower in E. coli compared with CNS, Staph. aureus, Strep. dysgalactiae, and E. faecalis, and the WGA APC MFI was significantly lower in E. coli compared with CNS, Staph. aureus, Strep. dysgalactiae, Strep. uberis, and E. faecalis (Figure 5).

When using the cut-off values for both AO FITC MFI and WGA APC MFI determined for the in-house bacteria cultures, the sensitivity was 1 and the specificity was 0.74 for detection of gram-negative bacteria in milk samples, and $77 \%$ of the pathogens were gram-typed correctly; 3/17 CNS, 1/7 Staph. aureus, 1/1 Strep. agalactiae, 2/6 Strep. uberis, and 5/10 E. faecalis were classified incorrectly. However, based on the evaluation of ROC curves for the 53 mastitis cases, the identified cut-off values for the in-house bacterial cultures were most likely overestimated (Figure 4). Using the cut-off values determined from the ROC curves based on the milk samples AAO FITC 9,037 MFI [sensitivity $=1(1$; 


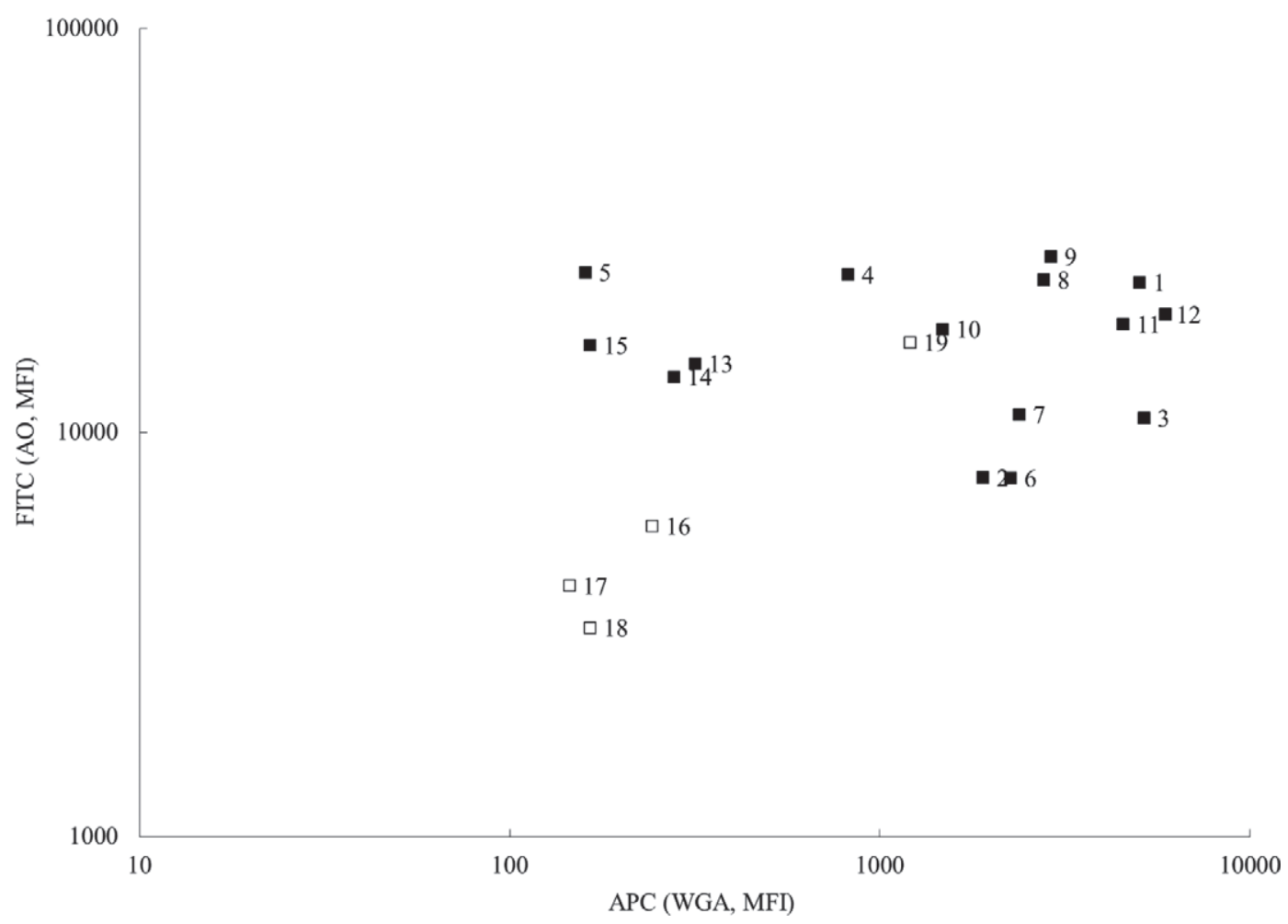

Figure 3. In-house bacterial cultures are plotted with respect to fluorescein isothiocyanate (FITC) and allophycocyanin (APC) mean fluorescence intensity (MFI). The identification number refers to the individual bacterial cultures listed in Table $1.1-3=$ Staphylococcus aureus; $4-6=$ CNS; $7=$ Streptococcus agalactiae $; 8-9=$ Streptococcus dysgalactiae; $10-12=$ Streptococcus uberis $; 13-15=$ Enterococcus spp.; $16=$ Escherichia coli $; 17=$ Klebsiella pneumoniae $; 18=$ Serratia marcescens; $19=$ Pseudomonas aeruginosa . Gram-negative bacteria cultures are symbolized by open squares $(\square)$ and gram-positive bacteria cultures by filled squares $(\boldsymbol{\square})$. AO = acridine orange; WGA = wheat germ agglutinin.

$1)$, specificity $=0.72(0.6 ; 0.85)]$ and WGA APC 303 MFI [sensitivity $=1(1 ; 1)$, specificity $=0.94(0.85$; 1)]\}, both sensitivity and specificity would be 1 in the present study.

\section{DISCUSSION}

In the present study, a flow cytometry-based method was set up to detect and distinguish gram-negative and gram-positive mastitis-associated bacteria in milk samples from cows with clinical mastitis. Bacterial detection was achieved through preincubation and by diluting milk samples in connection with the preincubation and labeling procedures before flow analysis. This approach made it possible to separate bacteria from somatic cells and cell debris in the milk when labeling with AO. Gram-type was determined based on bacterial fluorescence intensity upon labeling with $\mathrm{AO}$ and biotin-conjugated APC streptavidin-WGA complexes. Staining intensity was affected by cell wall composition of the bacteria; generally, gram-negative bacteria that had a thin peptidoglycan layer surrounded by an outer lipopolysaccharide layer stained less intensively.
The present results indicate that it may be possible to detect and determine the gram-type of pathogenic bacteria in mastitis milk samples based on bacterial AO FITC and WGA APC fluorescence intensity. Using this fluorescent staining procedure, we confirmed that gram-negative bacteria stained less intensely with the WGA complex compared with gram-positive bacteria, as has previously been reported (Sizemore et al., 1990; Holm and Jespersen, 2003). Wheat germ agglutinin binds to $\mathrm{N}$-acetylglucosamine in the peptidoglycan layer, which is prevented in gram-negative bacteria, as WGA cannot penetrate the outer lipopolysaccharide layer. In addition, gram-negative bacteria also took up less AO. Previously, it has been shown that gram-negative bacteria stained with $\mathrm{AO}$ decolorized differently when subjected to ethyl alcohol or acetone (Fazii et al., 2002), indicating that the cell wall of gram-negative bacteria was less capable of retaining AO.

In a prevalence study performed in Finland, the most common bacterial pathogens isolated from quarter milk samples were CNS, Corynebacterium bovis, Staph. aureus, Strep. uberis, Enterococcus spp., coliforms, Strep. dysgalactiae, and Strep. agalactiae, in the order 
A

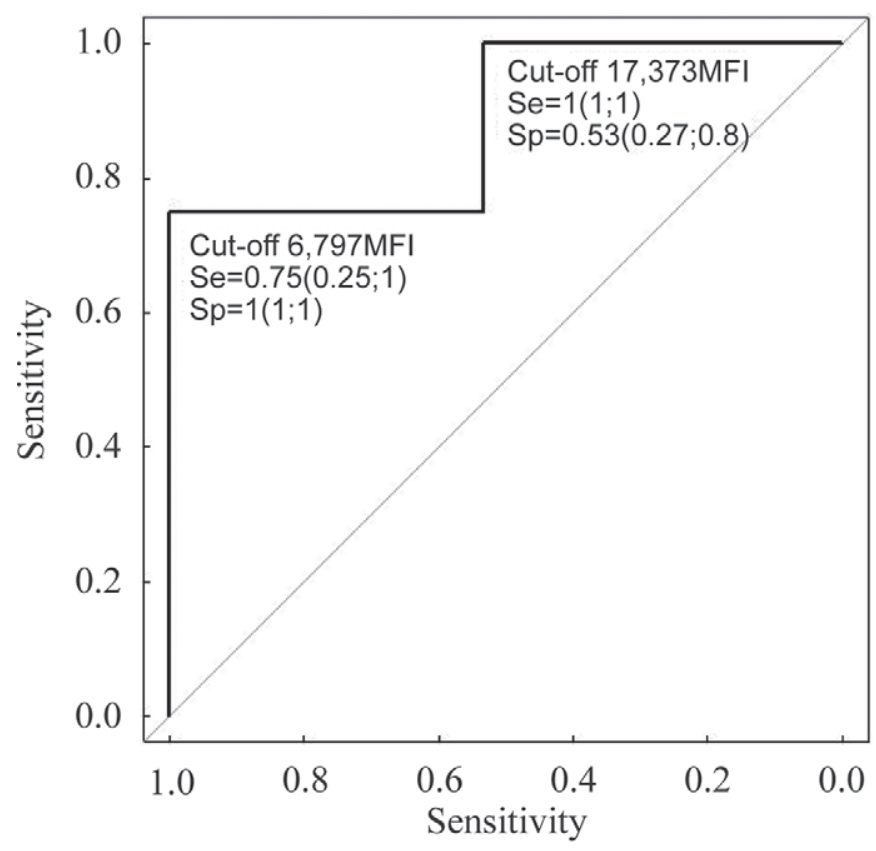

C

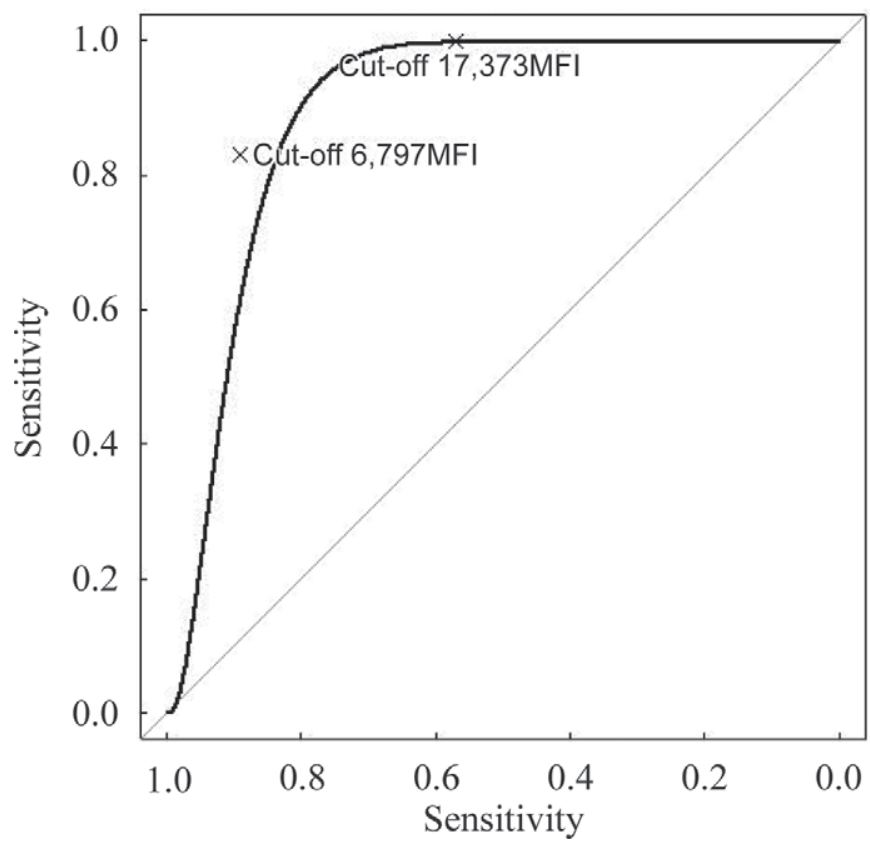

B

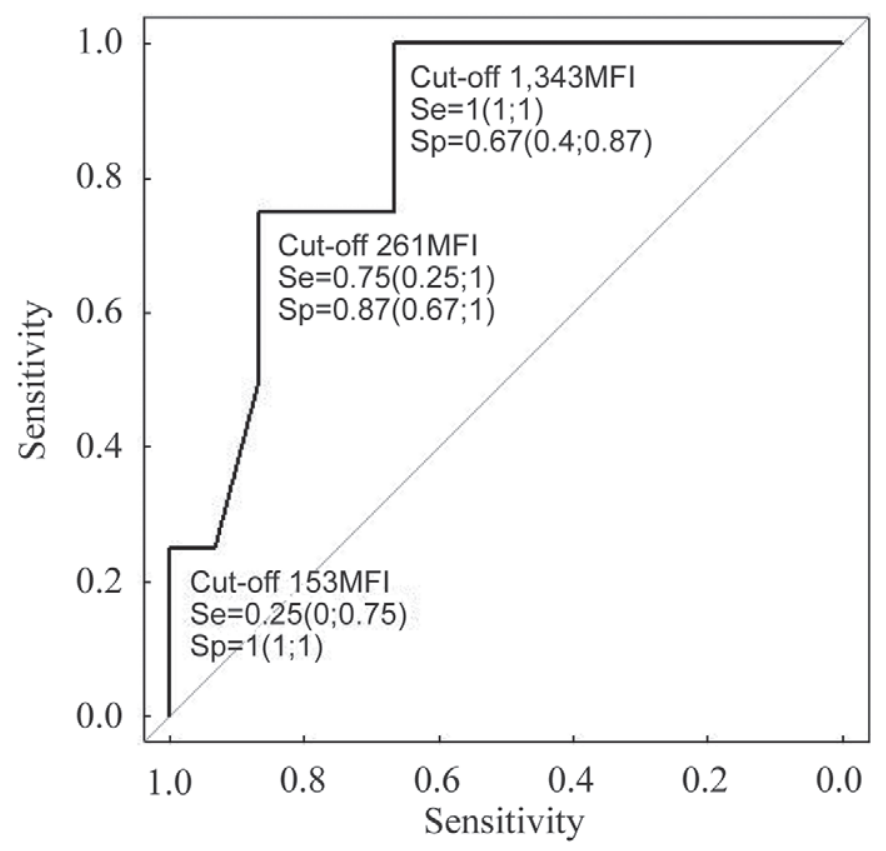

D

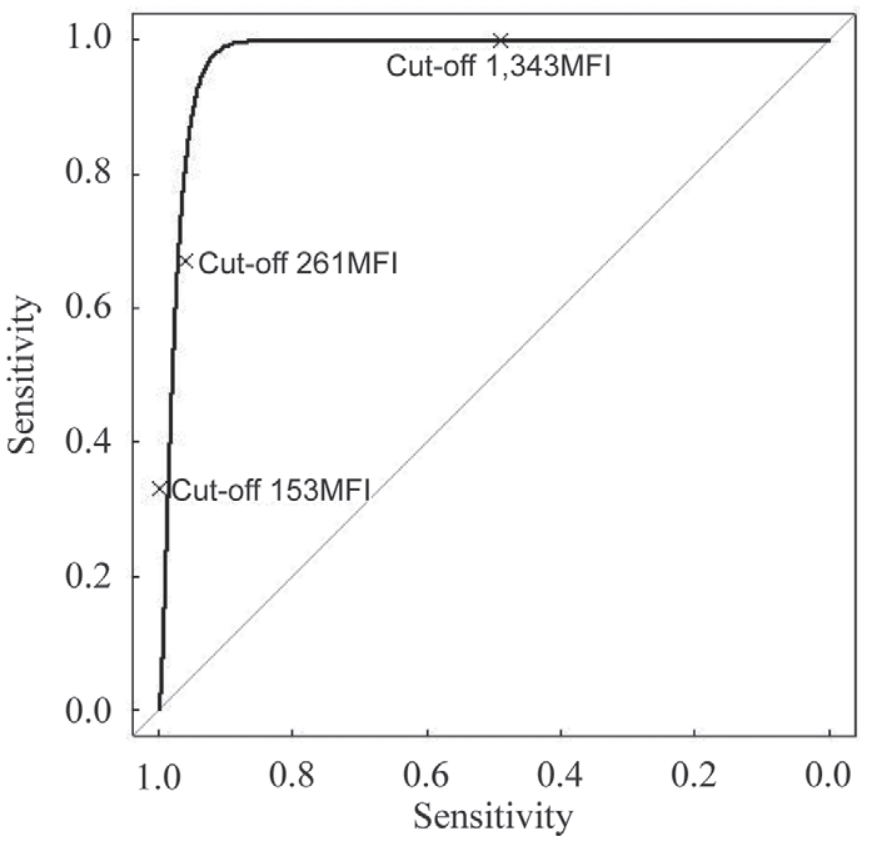

Figure 4. (A) and (B): receiver operating characteristic (ROC) curves constructed for acridine orange (AO) and wheat germ agglutinin (WGA), respectively, based on the 19 in-house bacterial cultures. (C) and (D): ROC curves (smooth function applied) for AO and WGA, respectively, based on the 53 mastitis milk samples. In mastitis milk samples, the AO fluorescein isothiocyanate (FITC) cut-off value of 9,037 mean fluorescence intensity (MFI) had a sensitivity [median (CI)] of $1(1 ; 1)$ and a specificity [median (CI)] of $0.72(0.6 ; 0.85)$, and the WGA allophycocyanin (APC) cut-off value of 303 MFI had a sensitivity of $1(1 ; 1)$ and a specificity of $0.94(0.85 ; 1)$ for detection of gram-negative mastitis cases. By using the 2 cut-off values in combination, a sensitivity (Se) and specificity (Sp) of 1 were obtainable. 


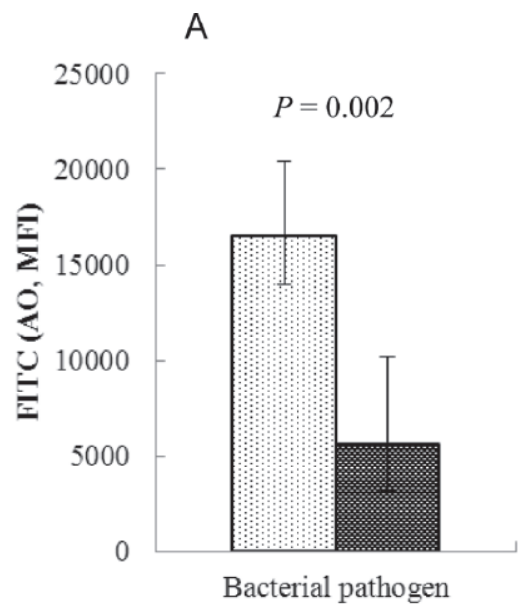

$\square$ Gram-positive $\quad$ Gram-negative

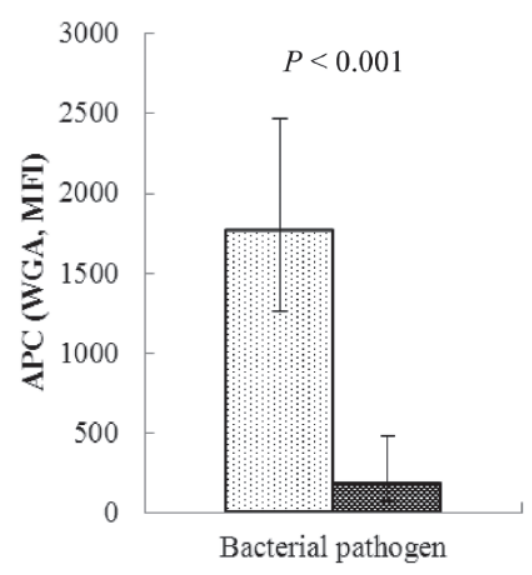

$\square$ Gram-positive $\quad$ Oram-negative

B

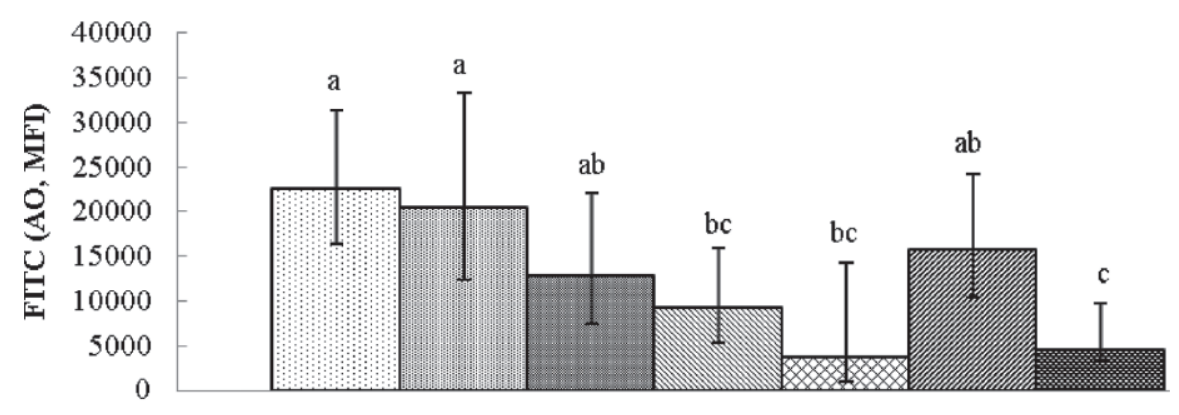

Bacterial pathogen
$\square \operatorname{CNS}(\mathrm{n}=17)$
田Staph. aureus $(\mathrm{n}=7)$
$\square$ Strep. dysgalactiae $(\mathrm{n}=6)$
$\mathbb{\$}$ Strep. uberis $(\mathrm{n}=6)$
$\otimes$ Strep. agalactiae $(\mathrm{n}=1)$
E. faecalis $(\mathrm{n}=10)$

ㅇㅛㅛ $\operatorname{coli}(\mathrm{n}=6)$

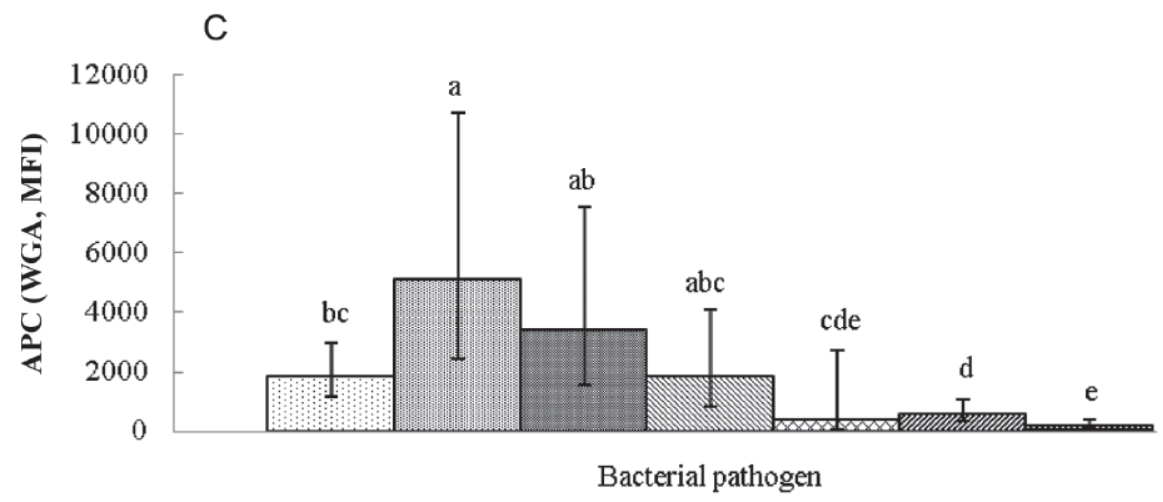
๑CNS $(\mathrm{n}=17)$
$\square$ Staph. aureus $(\mathrm{n}=7)$
$\square$ Strep. dysgalactiae $(\mathrm{n}=6)$

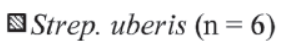
$\triangle$ Strep. agalactiae $(\mathrm{n}=1)$
E. faecalis $(\mathrm{n}=10)$
圆E. $\operatorname{coli}(\mathrm{n}=6)$

Figure 5. (A) The median acridine orange (AO) fluorescein isothiocyanate (FITC) and wheat germ agglutinin (WGA) allophycocyanin (APC) mean fluorescence intensity (MFI) for the 6 gram-negative and the 47 gram-positive bacterial pathogens in mastitis milk samples; (B) the median AO FITC MFI and (C) the median WGA APC MFI for each bacterial pathogen in the mastitis milk samples. Significant differences in MFI among bacterial pathogens are indicated by the different letters (a-e). Staph. $=$ Staphylococcus; Strep. $=$ Streptococcus; E. faecalis $=$ Enterococcus faecalis; E. coli $=$ Escherichia coli. 
mentioned (Pitkälä et al., 2004). In the present study, the in-house bacterial cultures and mastitis cases were selected to represent the most common bacterial udder infections, although the study lacks results for $C$. bovis, as it is considered a minor mastitis pathogen (Pitkälä et al., 2004). Escherichia coli, Klebsiella pneumonia, Serratia marcescens, and Pseudomonas aeruginosa were included to represent different gram-negative strains.

The gram-negative bacterium $P$. aeruginosa was observed to stain intensively with the biotin-conjugated APC streptavidin-WGA complex, which has also been reported by Sizemore et al. (1990). In addition, P. aeruginosa also stained intensely with $\mathrm{AO}$. Consequently, $P$. aeruginosa increased the AO FITC and WGA APC cut-off values determined for the in-house bacterial cultures (no. 19; Figure 2). Mastitis cases did not include infections caused by $P$. aeruginosa and, therefore, specificities were higher at lower cut-off values for $\mathrm{AO}$ FITC and WGA APC MFI, when looking at the ROC curves for the milk samples.

In mastitis milk samples, gram-negative E. coli differed significantly with respect to AO FITC and WGA APC MFI compared with the gram-positive Staphylococcus spp., Strep. dysgalactiae, and E. faecalis. In addition, E. coli differed compared with Strep. uberis with respect to WGA APC MFI. However, the single gram-positive Strep. agalactiae mastitis case included in the study stained similar to E. coli, which was not observed with the in-house Strep. agalactiae strain (no. 7; Figure 3), which stained as was expected for gram-positive bacteria. Most gram-positive bacteria have carbohydrate polymers incorporated into their cell walls and these carbohydrate polymers are highly diverse and often species or strain specific (Weidenmaier and Peschel, 2008). Holm and Jespersen (2003) argue that lowering $\mathrm{pH}$ affects the binding of WGA for some gram-positive bacteria, as it affects the rigid structure of the glycopolymer teichoic acid, thereby increasing access to the WGA binding site. However, in the present study we did not lower $\mathrm{pH}$ to enforce WGA binding. Misclassification of Strep. agalactiae with the present method is a cause for concern, as it is a contagious pathogen of major economic importance and, furthermore, an ongoing Danish surveillance program exists for this pathogen (Mweu et al., 2012). As Strep. agalactiae multiplies in chain formation, the bacterium can be separated from gram-negative bacteria based on its FSC and SSC position during flow analysis (S. N. Langerhuus, unpublished data). Further analysis with additional Strep. agalactiae mastitis cases or isolates must be carried out to verify if this atypical gram classification involves other strains of Strep. agalactiae.
The present flow cytometry-based method was envisioned as a fast on-site solution to be used on fresh milk samples obtained from cows with clinical mastitis, potentially as a cow-site analysis performed by the farmer in the barn. In our study, analyses were conducted on frozen milk samples, which may delay initial bacterial growth and the number of viable bacteria for some species (Schukken et al., 1989; Sánchez et al., 2003); consequently, we used 24-h preincubations. Therefore, it is relevant to analyze fresh mastitis milk samples using shorter preincubation times and repeated measurements to determine how early bacteria can be detected and a gram-type diagnosis made. Moreover, as the bacterial concentrations in milk vary depending on bacterial species and time of sampling in relation to disease kinetics (Schukken et al., 2011), preincubation times are expected to vary from 1 to 2 to $48 \mathrm{~h}$.

In accordance with our observations (S. N. Langerhuus, unpublished data), the bacterial detection limit with flow cytometry has been reported to be $\leq 10^{4}$ bacteria/mL (Gunasekera et al., 2000; Gruden et al., 2004). Bacterial concentrations in quarter milk samples from cows with clinical mastitis have been reported to reach $1 \times 10^{6}$ to $1 \times 10^{8}$ bacteria/mL (Jeffrey and Wilson, 1987; Leigh et al., 2010; Schukken et al., 2011). However, concentrations are often much lower, as cows are frequently sampled after the bacterial growth has peaked in the mammary gland (Dinsmore et al., 1992).

With the present method, milk samples were diluted 100-fold to circumvent the noise from high SCC. Subsequently, the preincubation step increased bacterial numbers, resulting in an even lower bacteria:SCC noise ratio. Moreover, the use of preincubation of milk samples before the standard culture technique has been documented to increase the probability of diagnosing some mastitis bacteria (Dinsmore et al., 1992; Sol et al., 2002; Artursson et al., 2010). For instance, a short preincubation time will increase the likelihood of identifying E. coli in mastitic milk samples (Dinsmore et al., 1992), whereas a long preincubation time before culturing will increase the percentage of cows diagnosed with mastitis caused by Staph. aureus (Artursson et al., 2010). Nevertheless, viability is a criterion for bacterial growth during preincubation. Thus, if a milk sample contains as little as 1 viable bacterium that multiplies during preincubation, it can be detected and gramtyped. Extended preincubation times may, however, be complicated by growth and additional noise from contaminant bacteria (Dinsmore et al., 1992).

Specificity of the present method may improve by incubating milk samples in selective growth mediums favoring gram-negative or gram-positive bacterial 
growth, and valuable information could be gained by introducing media that may differentiate Streptococcus spp. from Staphylococcus spp. Furthermore, introducing a medium with penicillin or other types of antibiotics along with a nonselective medium such as BHI may give additional information on antibiotic resistance among pathogens.

The present method cannot compete with the traditional culturing techniques or PCR technology with respect to bacterial identification. In contrast to the PCR method, this combined preincubation and fluorescent staining method has the potential to differentiate between living and dead bacteria and to include an antibiogram.

\section{CONCLUSIONS}

Bacteria in diluted and preincubated mastitis milk samples can be detected and gram-typed by $\mathrm{AO}$ and WGA fluorochrome labeling using flow cytometry. In the future, this method could potentially provide the dairy farmer or the attending veterinarian with on-site information on bacterial detection and gram-type in cases of clinical mastitis. At present, flow cytometry is accessible in minor portable units (Gruden et al., 2004), and with this technology the method could potentially be further developed for cow-side or online automatized solutions.

\section{ACKNOWLEDGMENTS}

The authors thank laboratory technicians Inger Marie Jepsen and Hanne Møller Purup (Department of Animal Science, Faculty of Science and Technology, Aarhus University, Tjele, Denmark) for conduction of flow analyses and classical bacterial procedures, respectively. In addition, we thank the participating herd managers for their cooperation. Financial support was granted by Lattec I/S (Hillerød, Denmark) and the Danish Ministry of Food, Agriculture and Fisheries (Copenhagen, Denmark).

\section{REFERENCES}

Arthi, K., B. Appalaraju, and S. Parvathi. 2003. Vancomycin sensitivity and $\mathrm{KOH}$ string test as an alternative to gram staining of bacteria. Indian J. Med. Microbiol. 21:121-123.

Artursson, K., M. Nilsson-Öst, and W. K. Persson. 2010. An improved method to culture Staphylococcus aureus from bovine milk. J. Dairy Sci. 93:1534-1538.

Bunthof, C. J., and T. Abee. 2002. Development of a flow cytometric method to analyze subpopulations of bacteria in probiotic products and dairy starters. Appl. Environ. Microbiol. 68:2934-2942.

Dinsmore, R. P., P. B. English, R. N. Gonzalez, and P. M. Sears. 1992. Use of augmented cultural techniques in the diagnosis of the bacterial cause of clinical bovine mastitis. J. Dairy Sci. 75:2706-2712.
Fazii, P., E. Ciancaglini, and G. Riario Sforza. 2002. Differential fluorescent staining method for detection of bacteria in blood cultures, cerebrospinal fluid and other clinical specimens. Eur. J. Clin. Microbiol. Infect. Dis. 21:373-378.

Flint, S., K. Walker, B. Waters, and R. Crawford. 2007. Description and validation of a rapid $(1 \mathrm{~h})$ flow cytometry test for enumerating thermophilic bacteria in milk powders. J. Appl. Microbiol. 102:909-915.

Fogsgaard, K. K., C. M. Røntved, P. Sorensen, and M. S. Herskin. 2012. Sickness behavior in dairy cows during Escherichia coli mastitis. J. Dairy Sci. 95:630-638.

Gruden, C., S. Skerlos, and P. Adriaens. 2004. Flow cytometry for microbial sensing in environmental sustainability applications: Current status and future prospects. FEMS Microbiol. Ecol. 49:37-49.

Gunasekera, T. S., P. V. Attfield, and D. A. Veal. 2000. A flow cytometry method for rapid detection and enumeration of total bacteria in milk. Appl. Environ. Microbiol. 66:1228-1232.

Gunasekera, T. S., D. A. Veal, and P. V. Attfield. 2003. Potential for broad applications of flow cytometry and fluorescence techniques in microbiological and somatic cell analyses of milk. Int. J. Food Microbiol. 85:269-279.

Holm, C., and L. Jespersen. 2003. A flow-cytometric gram-staining technique for milk-associated bacteria. Appl. Environ. Microbiol. 69:2857-2863

Jeffrey, D. C., and J. Wilson. 1987. Effect of mastitis-related bacteria on total bacterial count of bulk milk supplies. Int. J. Dairy Technol. $2: 23-26$.

Koskinen, M. T., J. Holopainen, S. Pyörälä, P. Bredbacka, A. Pitkälä, H. W. Barkema, R. Bexiga, J. Roberson, L. Sølverød, R. Piccinini, D. Kelton, H. Lehmusto, S. Niskala, and L. Salmikivi. 2009. Analytical specificity and sensitivity of a real-time polymerase chain reaction assay for identification of bovine mastitis pathogens. J. Dairy Sci. 92:952-959.

Leigh, J. A., S. A. Egan, P. N. Ward, T. R. Field, and T. J. Coffey. 2010. Sortase anchored proteins of Streptococcus uberis play major roles in the pathogenesis of bovine mastitis in dairy cattle. Vet. Res. 41:63.

Madigan, M. T., J. M. Martinko, P. V. Dunlap, and D. P. Clark. 2009. Brock Biology of Microorganisms. 12th ed. Pearson Education Inc., San Francisco, CA.

Mweu, M. M., S. S. Nielsen, T. Halasa, and N. Toft. 2012. Annual incidence, prevalence and transmission characteristics of Streptococcus agalactiae in Danish dairy herds. Prev. Vet. Med. 106:244-250. http://dx.doi.org/10.1016/j.prevetmed.2012.04.002.

Pinzón-Sánchez, C., and P. L. Ruegg. 2011. Risk factors associated with short-term post-treatment outcomes of clinical mastitis. J. Dairy Sci. 94:3397-3410.

Pitkälä, A., M. Haveri, S. Pyörälä, V. Myllys, and T. Honkanen-Buzalski. 2004. Bovine mastitis in Finland 2001-Prevalence, distribution of bacteria, and antimicrobial resistance. J. Dairy Sci. 87:2433-2441.

Rasmussen, D. B., K. Fogsgaard, C. M. Røntved, I. C. Klaas, and M. S. Herskin. 2011. Changes in thermal nociceptive responses in dairy cows following experimentally induced Escherichia coli mastitis. Acta Vet. Scand. 53:32.

R Development Core Team. 2012. R: A Language and Environment for Statistical Computing. Version 2.14.2. R Foundation for Statistical Computing, Vienna, Austria.

Sánchez, A., A. Contreras, J. Jiménez, C. Luengo, J. C. Corrales, and C. Fernández. 2003. Effect of freezing goat milk samples on recovery of intramammary bacterial pathogens. Vet. Microbiol. 94:71-77.

Schukken, Y. H., F. J. Grommers, J. A. Smit, D. Vandegeer, and A. Brand. 1989. Effect of freezing on bacteriologic culturing of mastitis milk samples. J. Dairy Sci. 72:1900-1906.

Schukken, Y. H., J. Günther, J. Fitzpatrick, M. C. Fontaine, L. Goetze, O. Holst, J. Leigh, W. Petzl, H.-J. Schuberth, A. Sipka, D. G. E. Smith, R. Quesnell, J. Watts, R. Yancey, H. Zerbe, A. Gurjar, R. N. Zadoks, and H. M. Seyfert. 2011. Host-response patterns of 
intramammary infections in dairy cows. Vet. Immunol. Immunopathol. 144:270-289.

Seegers, H., C. Fourichon, and F. Beaudeau. 2003. Production effects related to mastitis and mastitis economics in dairy cattle herds. Vet. Res. 34:475-491.

Shome, B. R., S. Das Mitra, M. Bhuvana, N. Krithiga, D. Velu, R. Shome, S. Isloor, S. B. Barbuddhe, and H. Rahman. 2011. Multiplex PCR assay for species identification of bovine mastitis pathogens. J. Appl. Microbiol. 111:1349-1356.

Sizemore, R. K., J. J. Caldwell, and A. S. Kendrick. 1990. Alternate gram staining technique using a fluorescent lectin. Appl. Environ. Microbiol. 56:2245-2247.
Sol, J., O. C. Sampimon, E. Hartman, and H. W. Barkema. 2002. Effect of preculture freezing and incubation on bacteriological isolation from subclinical mastitis samples. Vet. Microbiol. 85:241249.

Weidenmaier, C., and A. Peschel. 2008. Teichoic acids and related cellwall glycopolymers in Gram-positive physiology and host interactions. Nat. Rev. Microbiol. 6:276-287. 